\title{
Comparative Study Regarding Thermal Behaviour of Mixtures Based on Hydroxyapatite and Methacrylate for Dental Use
}

\author{
MADALINA MATEESCU ${ }^{1 \#, ~ G A B R I E L A ~ V L A S E ~}{ }^{1 *}$, DANIELA JUMANCA ${ }^{2 *}$, \\ ATENA GALUSCAN ${ }^{2}$, CLAUDIU AVRAM ${ }^{3}$, TITUS VLASE ${ }^{1 \#}$ \\ ${ }^{1}$ Research Centre for Thermal Analysis in Environmental Problems, West University of Timisoara, 16 Pestalozzi Str., 300115, Timisoara, \\ Romania \\ ${ }^{2}$ University of Medicine and Pharmacy “Victor Babes", Faculty of Dental Medicine, 2 Eftimie Murgu Sq., 300041, Timisoara, Romania \\ ${ }^{3}$ West University of Timisoara, Physical Therapy and Special Motricity Department, 4 Vasile Parvan Blvd., 300223, Timisoara, Romania
}

\begin{abstract}
Theobromine (Th) was documented during the last decades for its important role in the prevention of dental caries, having this role due to its antibacterial action against the Streptococcus mutants and S. sanguinis, thus reducing the formation of dental biofilm on the teeth surface. Thermally induced interactions of theobromine in 1:1 mass ration binary mixture with different types of Poly(methyl methacrylate) based materials and the induced interactions between Poly(methyl methacrylate) based materials and HA were performed using thermal analysis and FTIR spectroscopy. This study aims to be a preliminary study for various mixtures of HA/methacrylate-based materials and Th with usage in dental applications. The instrumental techniques used can be successfully applied in the characterization of dental materials and can lead to conclusions on how to use them.Studies have led to the conclusion that Th can be used for the treatment of early decay by incorporation into the polymer material. It is recommended to use these materials as successive layers (Th with HA and after that dental material).
\end{abstract}

Keywords: theobromine, poly(methyl methacrylate), hydroxyapatite, thermally induced interactions, thermal analysis, FTIR study, SEM analysis

\section{Introduction}

For decades, poly(methyl methacrylate) has been commonly usedin dentistry and many other fields. poly(methyl methacrylate) (PMMA) is generally referred to as a synthetic resin and is usually produced by polymerization of the methyl-methacrylate monomer [1]. PMMA is widely used in the dental field, especially due to its biocompatibility, followed by resistance to humidity and weathering, acceptable aesthetics, low cost, easy processing, good flexibility and, also, for lofty surface resistance [2,3]. Recent studies show a minimal risk of allergy for prosthetic carriers [4], but residual monomer (methyl methacrylate MMA) can cause irritant or allergic reactions in some patients with mouth guards [5]. Resins are also used as in-office desensitizing agents to improve the symptons of dentinal hypersensitivity [6].

Also the most commonly used materials in dentistry based on methacrylate are 2,2-bis[p-(2)hydroxy-3'-methacryloxypropoxy)phenylene]propane (Bis-GMA) and 1,6-bis(methacryloxy-2-ethoxycarb-onylamino)-2,4,4-trimethylhexane (UDMA) (See structure of Bis-GMA and UDMA in Figure 1 and 2). The stiff molecular structure of Bis-GMA and also the $\mathrm{OH}$ groups ensure low cure contraction, high polymer modulus and a very good adhesion to tooth enamel [7]. At the same time, UDMA is used for lower viscosity and also for possibility of forming strong hydrogen bonds due to urethane linkage. These hydrogen bonds play an important role in the durability of the composite's matrix [8].

Hydroxyapatite $(\mathrm{HA}) \mathrm{Ca}_{10}\left(\mathrm{PO}_{4}\right)_{6}(\mathrm{OH})_{2}$ has acrystal unit cell comprisedof two entities [9, 10]. It is the main inorganic component of teeth and bones [11,12], therefore the synthetic HA also showed a very good bioactivity. Hydroxyapatite (HA) can be used in dental implants as a coating material applied to 
their surface by plasma spraying. This process is recommended for the improvement of the implant fixation on the surrounding bone [13].

Theobromine $\left(\mathrm{C}_{7} \mathrm{H}_{8} \mathrm{~N}_{4} \mathrm{O}_{2}\right)$ [Th] is a usually known as xantheose [14] and is a bitter alkaloid of themethylxanthine family (3,7-dimethylxanthine), see the structure in Figure 3, it is a crystalline white water-soluble powder found mainly in cocoa, chocolate and Camellia sinensis green tea leaves [15].

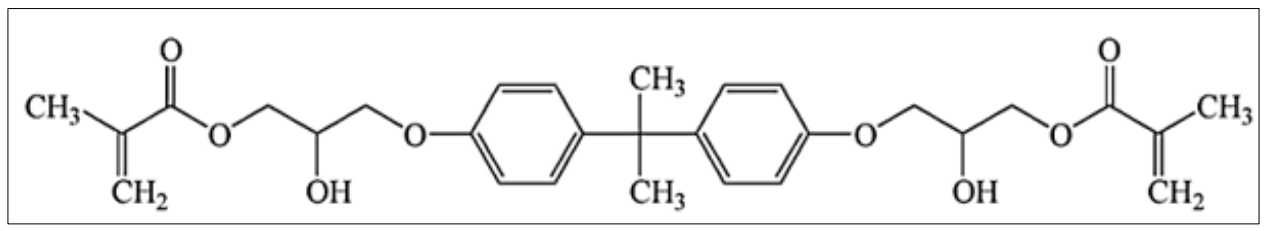

Figure 1. Structure of Bis-GMA (2,2-bis[p-(2`-hydroxy-3`-methacryloxypropoxy)phenylene]propane)<smiles>C=C(C)C(=O)OCCOC(=O)NCCC(C)CC(C)(C)CNC(=O)OCCOC(=O)C(=C)C</smiles>

Figure 2. Structure of UDMA (1,6-bis(methacryloxy-2-ethoxycarb- onylamino)-2,4,4trimethylhexane)<smiles>Cn1cnc2c1c(=O)[nH]c(=O)n2C</smiles>

Figure 3. Structure of theobromine $\mathrm{C}_{7} \mathrm{H}_{8} \mathrm{~N}_{4} \mathrm{O}_{2}$

The current study is based on tracking the interactions that might arise between different types of HA (bone, synthesis) or Th and different materials based on methacrylate that are used for teeth reconstruction.

Despite a better understanding of materials and chemistry, and recent improvements inphysical properties, no material was found to be ideal for any dental application [16].

For example, silver amalgam has been used for dental restoration for more than a century; however, there has been a major concern regarding mercury toxicity in amalgam restorations for many years [1720]. The composite restorative materials have promising aesthetics. In recent years there has been a drastic evolution of restoration materials, particularly in tooth colour materials. Nanotechnologies have been applied for the manufacturing of dental composites (nanocomposites) [12, 21-23], glass-ionomers cements (nano-ionomers), endodontic sealers and tooth regeneration.

Nanocomposites are composed of two or more materials that include a matrix material and nanoscale particles. The matrix should be a biocompatible polymeric, metallic, or ceramic material. In nanocomposites, it is possible to operate mechanical properties by incorporating secondary nanoparticles to obtain the same characteristic features of natural bone [24, 25].

The properties of nanostructured materials are completely controlled by their synthesis method, their processing means and their chemistry [26]. It has been acknowledged that the intrinsic molecular identification of the molecules is governing the formation, morphological development and crystallography of the nanocomposites [27].

\section{Materials and methods}

The requirements for an acceptable cavity filling material are many, but one of the most important is biocompatibility. In addition to certain biological requirements, such as cariostatic properties, lack of pulp irritability or systemic toxicity, a filling material should possess low water absorption and should not dissolve in the oral fluids [28]. 
Materials based on methacrylate used during this study are Nanofil and Reality, both materials are frequently used in dental area. Nanofil is recommended for anterior and limited posterior restorations and is based on urethane dimethacrylate-resin and inorganic filler particles $<1.0 \mu \mathrm{m}$.

In terms of Reality, materials is generally recommended also for anterior and posterior restorations, it is also based on BIS-GMA and contains inorganic particles of $0.05-1.5 \mu \mathrm{m}$.

The HA used is a Biotiss biomaterial (Cerabone) originated from natural bovine bone. The active substance, theobromine [Th], was purchased from Sigma.

The binary mixtures between HA and the two materials were obtain by grinding and mixing for 5 min under environmental conditions, the mass ratio between the components was 1:1. Binary mixtures of Nanofil and Reality materials with theobromine (Th) were made with two mass ratios, 1:1 and 1:2. The mixtures were prepared in the same way as for the mixtures with HA.

The analyses were performed for each material separately, for the binary mixtures between them, as well as for the photopolimerized materials/ mixtures. The analysis of photopolymerized binary materials and mixtures was performed in order to evaluate the possibility of release of the active substance, respectively the possibility of binding HA with the bone structure.

\section{FTIR- UATR spectra}

FT-IR/UATR spectroscopy of materials based on methacrylate and also for HA and Th was performed using one PerkinElmer Spectrum 100 FT-IR Spectrometer with UATR.

\section{TG analysis}

The thermal stability of the individual material and for binary mixture (1:1 and 1:2) was recorded in air atmosphere up to $500^{\circ} \mathrm{C}$ at a heating rate, $\beta=10^{\circ} \mathrm{C} \cdot \mathrm{min}^{-1}$, dynamic air atmosphere $\left(100 \mathrm{~mL} \cdot \mathrm{min}^{-1}\right)$ and aluminum crucible on a TG/DTA DIAMOND Thermal Analyzer produced by Perkin Elmer.

\section{SEM/ EDAX}

SEM/ EDAX analysis was performed with Quanta FEG 250devices equipped with EDAX analyzer with Apollo SDD detector.

\section{Results and discussions}

This chapter highlights the results obtained from the preparation of the samples for the analysis methods described in the Materials and methods chapter.

Thermogravimetrical results:

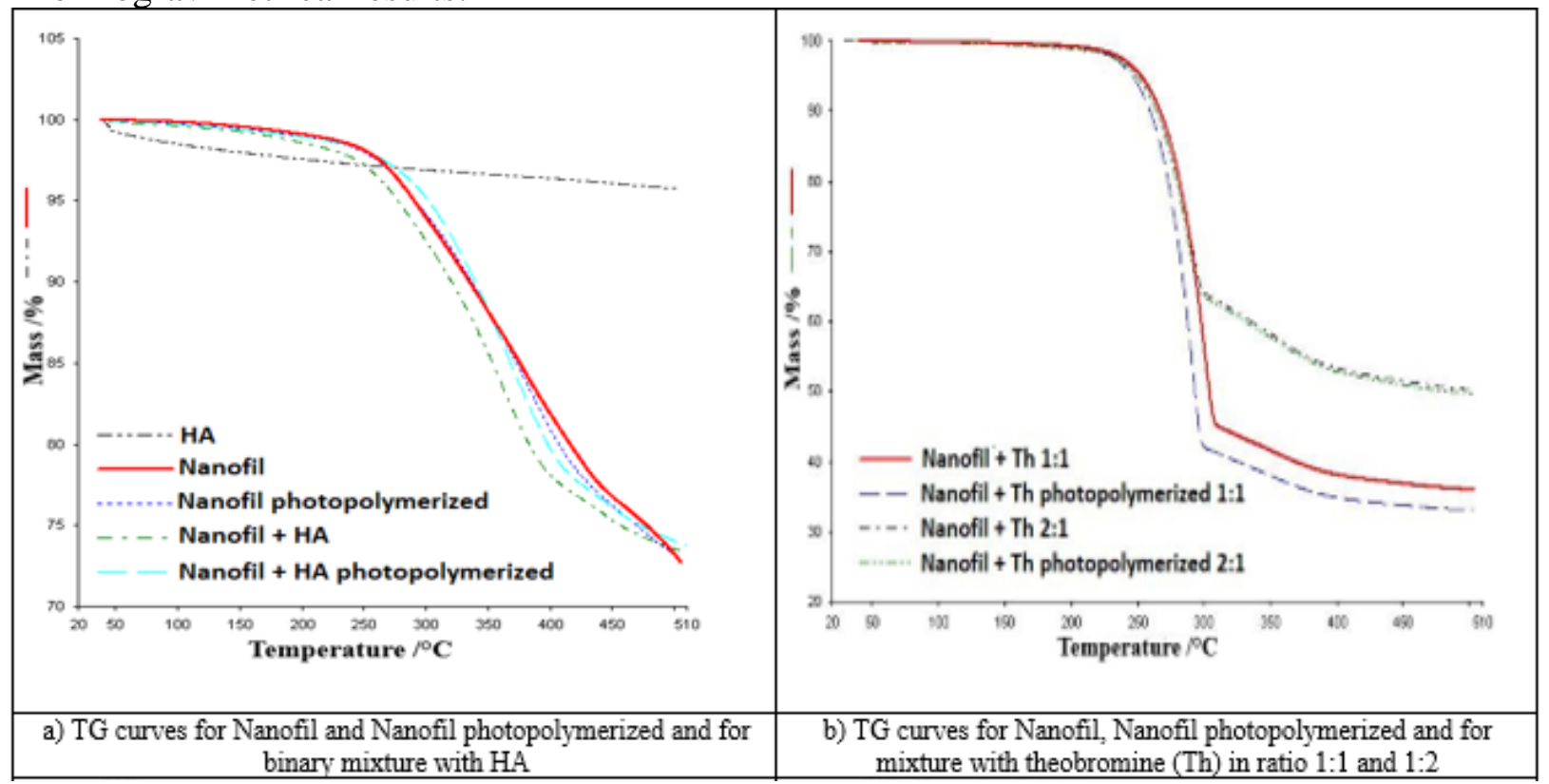




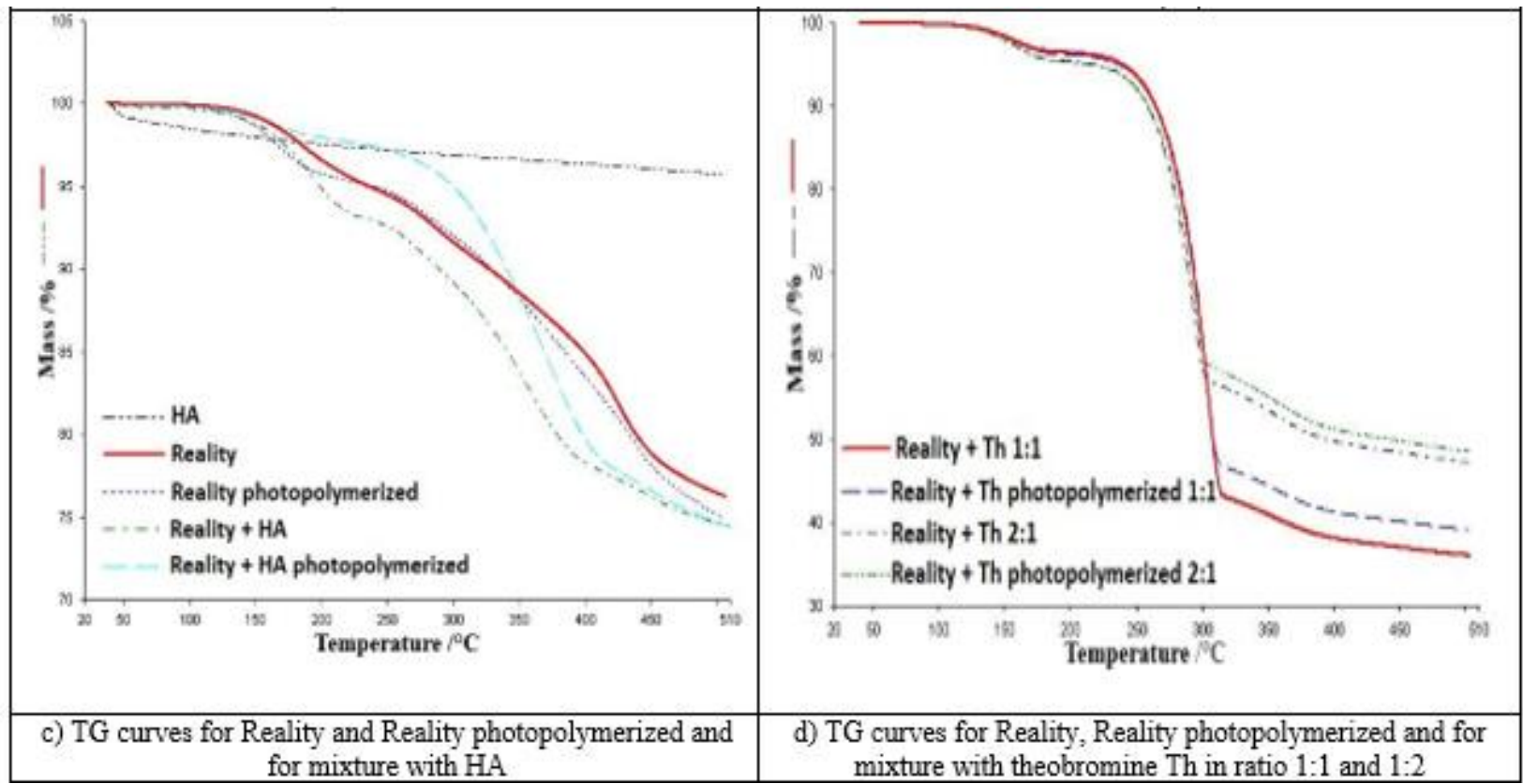

Figure 4. TG curves for Nanofil and Reality materials nonphotopolymerized/photopolymerized and the binary mixture of both material with HA and with Th

During the thermal degradation of Nanofil material three degradation processes were observed. The first process takes place in the range $199.51-311.03^{\circ} \mathrm{C}$ with a mass loss of $6.30 \%$. The second process started at $312.36^{\circ} \mathrm{C}$ and ended at $359.77^{\circ} \mathrm{C}$ during this range the mass loss was $5.62 \%$. The last degradation process, that took place during the degradation of the Nanofil material, is in the range $361.11-457.93^{\circ} \mathrm{C}$ with a loss of $10.58 \%$ of the mass sample.

The first step of decomposition observed in the case of Nanofil material can be attributed to the cleavage of the unreacted monomer units as well as the radical trapped in the copolymerstructure. The second degradation is attributed to the destruction of the small cycles formed intramolecularly in the polymer network. In the second stage of decomposition the main decomposition product is methacrylic acid. The third stage is attributed to the degradation of the main network to which the decomposition of the added inorganic compounds is added.

For Nanofil material photopolymerized were observed the same three processes with the following mentions: for the photopolymerized material the degradation started with approximately $10^{\circ} \mathrm{C}$ overthe degradation of the nonphotopolymerized material.

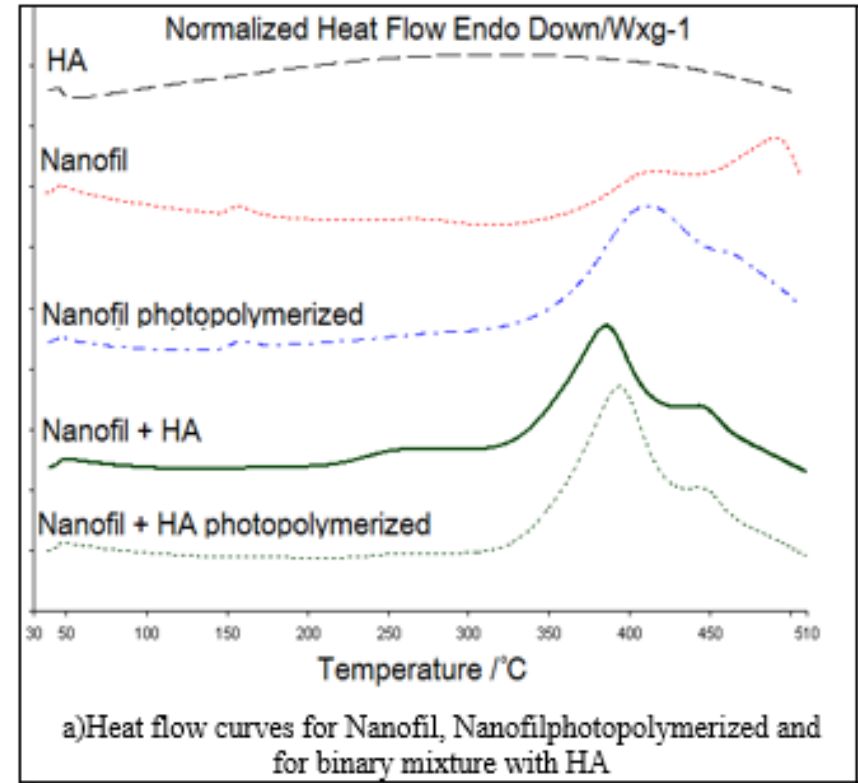

Mater. Plast., 58 (1), 2021, 1-10

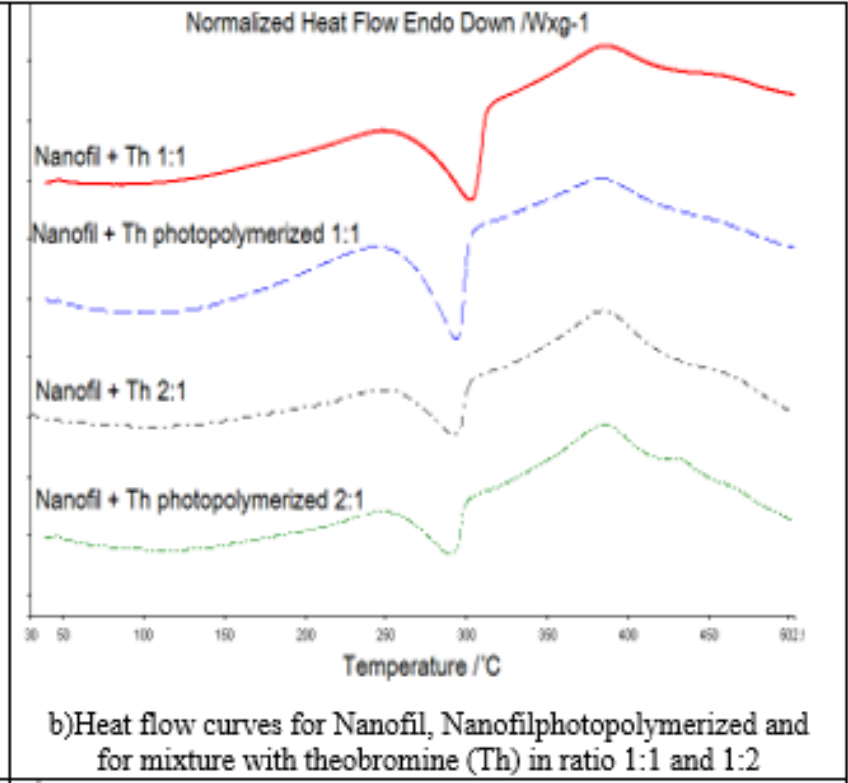




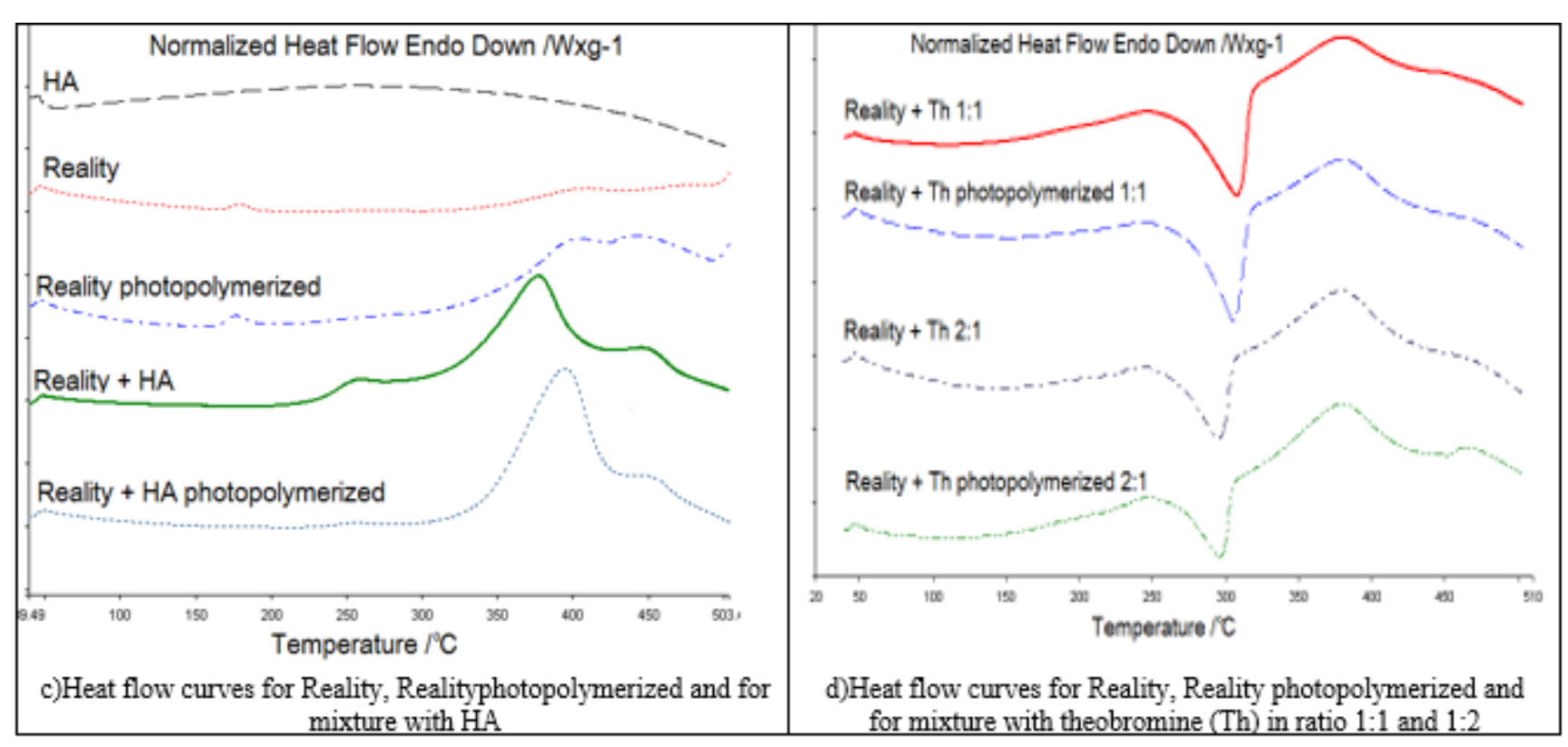

Figure 5. Heat flow curves for Nanofil and Reality materials nonphotopolymerized/ photopolymerized and the binary mixture of both material with HA and with theobromine (Th)

During the degradation of the binary mixture between Nanofil material and HA, a complex degradation process was observed. In the range $234.02-423.12^{\circ} \mathrm{C}$ are present two parallel processes with a mass loss of $21.13 \%$ of the total sample mass. Another degradation process, which started at $426.74{ }^{\circ} \mathrm{C}$, immediately follows these parallel processes, during this process a loss of $3.22 \%$ of the sample mass was observed.

Two degradation processes were observed for the photopolymerized binary mixture between Nanofil material and HA. The first one takes place in the range $224.80-418.72^{\circ} \mathrm{C}$ with a mass loss of $20.74 \%$. The second process of degradation of the binary mixture takes place in range $427.70-500^{\circ} \mathrm{C}$, the mass loss observed during the process is relatively insignificant $(3.61 \%)$.

From the thermal analysis it can be observed that the addition of HA leads to another structural organization resulting in a slightly different thermal behaviour of the samples. It can be observed that the mass loss, related to the second process, is higher and that it occurs at lower temperatures, which argue a loose polymeric structure.

During the degradation of the UDMA-based material with $\mathrm{TH}$, three degradation processes were observed. The first process started at $96.44^{\circ} \mathrm{C}$ and ended at $242.80^{\circ} \mathrm{C}$. During this process, the mass loss was $5.18 \%$. The second process took place in the range $244.13-327.67^{\circ} \mathrm{C}$. In this process the mass loss was $4.71 \%$. The last process started at $331.01^{\circ} \mathrm{C}$, ended at $494.08^{\circ} \mathrm{C}$ and the mass loss during the process was $13.13 \%$. In this case, the theobromine decomposition occurs with the last step of decomposition of the polymeric material. The addition of theobromine thermally destabilizes the polymeric material and its decomposition processes occur much faster.

During the degradation of the second material based on poly(methyl methacrylate) (Reality material)three degradation processes were observed, the first process started at $96.44^{\circ} \mathrm{C}$ and ended at $242.80^{\circ} \mathrm{C}$.During this process the mass loss was $5.18 \%$. The second process took place in the range $244.13-327.67^{\circ} \mathrm{C}$, during this process the mass loss was $4.71 \%$, the last process started at $331.01^{\circ} \mathrm{C}$ and ended at $494.08^{\circ} \mathrm{C}$ and the mass loss during the process was $13.13 \%$.

For Reality material, two degradation processes were observed. During the first degradation process, the mass loss was $4.38 \%$ and this took place in the range $113.81-222^{\circ} \mathrm{C}$. The second process seems to be a complex process, which was observed, beginning at $226.73^{\circ} \mathrm{C}$ and ended at $303.59^{\circ} \mathrm{C}$. This process was accompanied by a mass loss equal to $3.41 \%$.

In the case of Reality material-based on BisGMA, the first step of decomposition can be attributed to unreacted monomer units. The second decomposition process is represented by the thermal 
degradation of the polymer. Due to the rigid structure of bisphenol A, this material has a low probability of intramolecular cyclization, so that the process of degradation of the homopolymer takes place in a single step, the step corresponding to the degradation of the main network.

For the binary mixture between Reality and HA, three degradation processes were observed, the first occurring in the range of $115.68-232.23^{\circ} \mathrm{C}$ and the mass loss during the process was $6.483 \%$. For the second process the same behaviour can be observed as for the Reality material.

The photopolymerized mixture between Reality and HA presents two degradation stages, the first taking place in the range $103.62-227.20^{\circ} \mathrm{C}$ and the mass loss during this process was $2.16 \%$. The second process takes place in the range $230.66-426.73^{\circ} \mathrm{C}$, this process was accompanied by a mass loss equal to $19.87 \%$.

During the thermal degradation of Reality material with Th a high degradation process was observed in the range $214.76-316.26^{\circ} \mathrm{C}$, with a mass loss of $54.50 \%$. The process was accompanied by an endothermic effect with a maximum of $303.38^{\circ} \mathrm{C}, \Delta \mathrm{H}=249.63 \mathrm{~J} \mathrm{~g}^{-1}$.

For photopolymerized mixture (1:1) between Reality material and Th a degradation process was observed in the range $212.66-302.71{ }^{\circ} \mathrm{C}$ with a mass loss of $57.24 \%$. The decomposition process is endothermic with a $\Delta \mathrm{H}=240 \mathrm{~J} \cdot \mathrm{g}^{-1}$. After $308.44^{\circ} \mathrm{C}$ the degradation is slower and ends after $427.62^{\circ} \mathrm{C}$. This degradation was accompanied by an exothermic effect with $\Delta \mathrm{H}=-218.90 \mathrm{~J} \cdot \mathrm{g}^{-1}$.

For the binary mixture of Reality material with Th in the ratio 2:1 the same degradation process was observed as for the mixture of Reality material with Th in the ratio 1:1, but the mass loss was halved $(34.49 \%)$ and this is also confirmed by an endothermic process with $\Delta \mathrm{H}=136.75 \mathrm{~J} \cdot \mathrm{g}^{-1}$. In the case of Reality material, which is similar to the Nanofil material, the addition of HA and Theobromine leads to a more porous material with a lower thermal stability, namely, the decomposition processes that start at slightly lower temperatures.

\section{FT-IR study}

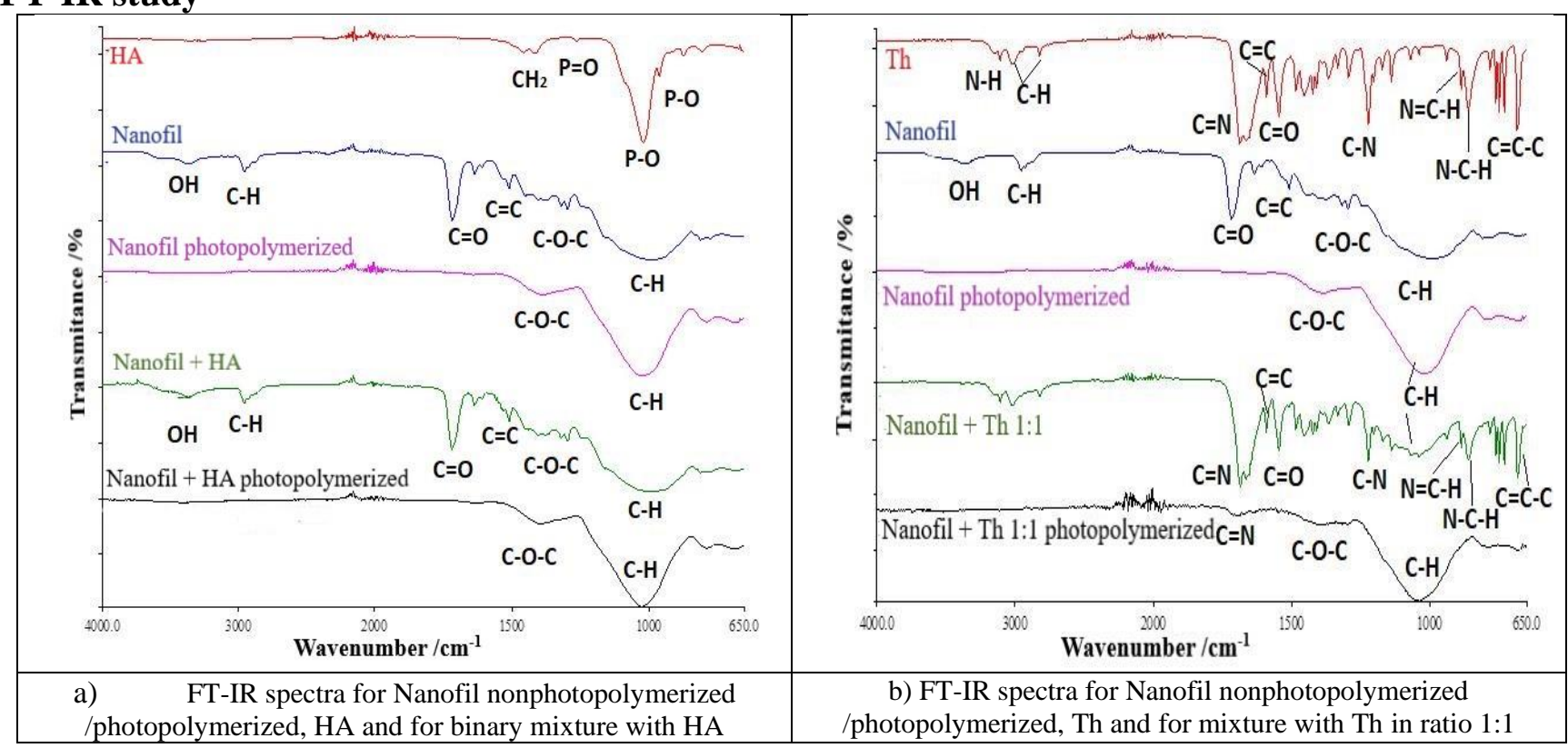

Figure 6. FT-IR spectra for Nanofil material nonphotopolymerized/photopolymerized, for HA,

Th and for the binary mixture of Nanofil material with HA and with Th

From FT-IR spectra of the binary mixture between Nanofil material and HA nonphotopolymerized specific peaks to Nanofil material can be observed, the appearance in the spectra of the specific bands from $3370 \mathrm{~cm}^{-1}$ assigned to $\mathrm{OH}$ stretching and from $2959 \mathrm{~cm}^{-1}$ assigned to $\mathrm{CH}$ from methyl group. Also the appearance of carbonyl $\mathrm{C}=\mathrm{O}$ stretching and aliphatic $\mathrm{C}=\mathrm{C}$ stretching can be observed in the range $1700-1510 \mathrm{~cm}^{-1}$. During the range $1210-1403 \mathrm{~cm}^{-1}$ peak can be assigned to $\mathrm{C}-\mathrm{O}-\mathrm{C}$ and the large peak 
from $1020 \mathrm{~cm}^{-1}$ can be attributing to $\mathrm{C}-\mathrm{H}$ link. The spectra of the binary mixture between Nanofil material and HA seems to be identical with the spectra of Nanofil material nonphotopolymerized. The peak characteristic to C-H link from $1020 \mathrm{~cm}^{-1}$ cover the peak for P-O link characteristic for HA material. For Nanofil and for binary mixture of it with HA both photopolymerized can be observed just peak from $1393 \mathrm{~cm}^{-1}$ assign to C-O-C link and peak from $1020 \mathrm{~cm}^{-1}$ characteristic to C-H and P-O link.

For binary mixture of Nanofil material with Th no differences was observed at the variation of ratio between Nanofil material and Th. For binary mixture of Nanofil material with Th without photopolymerization, specific peaks for Th were observed, the peak observed in at $3114 \mathrm{~cm}^{-1}$ is assigned to $\mathrm{N}$ $\mathrm{H}$ leakage from Th and also the peaks from 1664-1688 $\mathrm{cm}^{-1}$ are assigned to $\mathrm{C}=\mathrm{N}$. The range between $683-1223 \mathrm{~cm}^{-1}$ presents the same peaks as for Th.

For the photopolymerized binary mixture between Nanofil and Th, the characteristic peaks $\mathrm{C}=\mathrm{N}$ from $1688 \mathrm{~cm}^{-1}$ are observed. The $\mathrm{C}-\mathrm{H}$ peak at $1020 \mathrm{~cm}^{-1}$ characteristic for Nanofil material can be also observed.

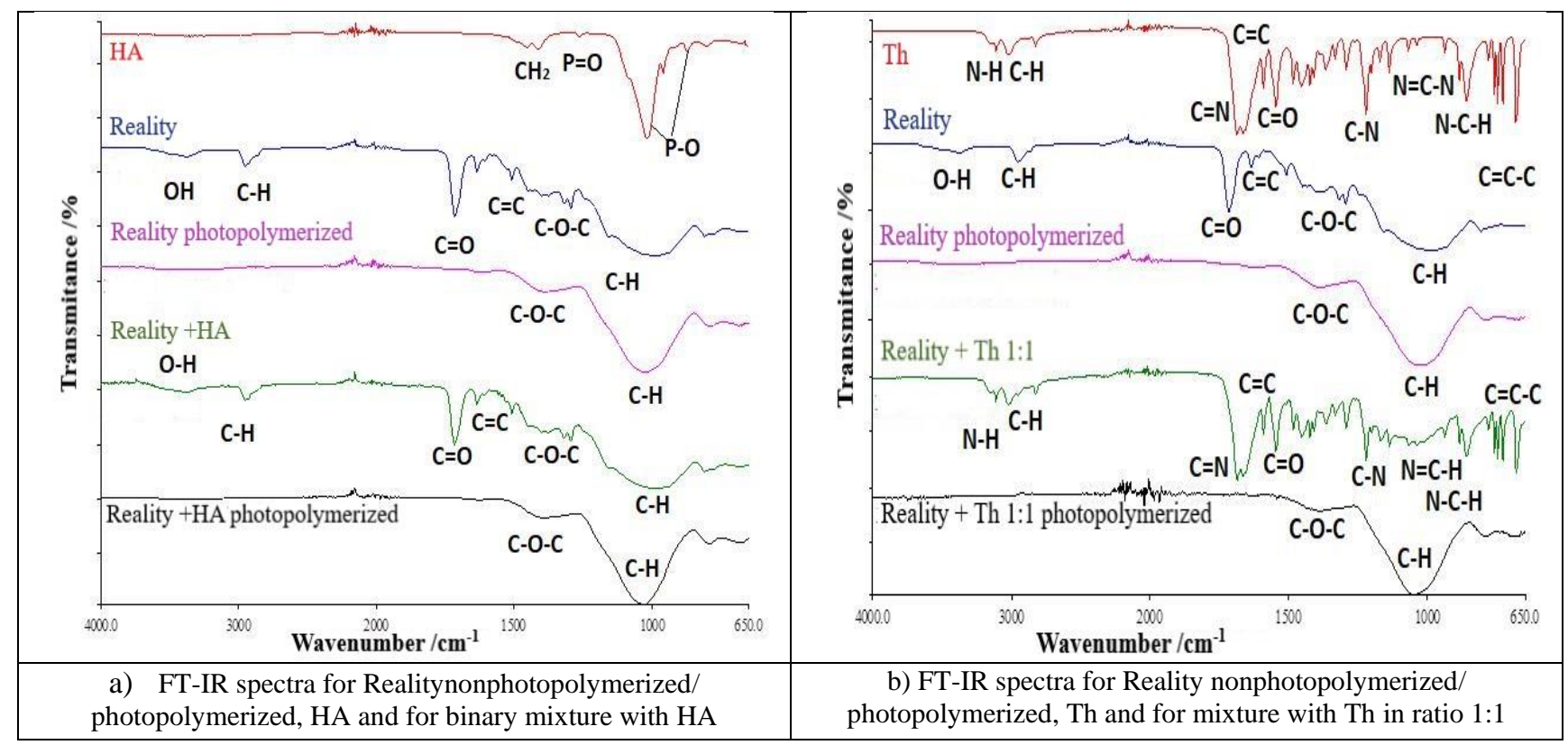

Figure 7. FT-IR spectra for Reality material nonphotopolymerized/photopolymerized for HA, Th and for the binary mixture of Reality material with HA and with Th

For FT-IR spectra of Reality material, the main difference is observed at $3300 \mathrm{~cm}^{-1}$, for this material this peak can be attributed to the NH vibration. The peaks of the spectra can be attributed to the different groups as follows: $2850 \mathrm{~cm}^{-1} \mathrm{CH}$ bonding; $1700-1510 \mathrm{~cm}^{-1}$ characteristic to $\mathrm{C}=\mathrm{O}$ and $\mathrm{C}=\mathrm{C}$ bonding; $1200-1310 \mathrm{~cm}^{-1}$ to C-O-C bonding.

From FT-IR spectra of the binary mixture between Th and Reality material, no differences in the spectra were observed during the variation of the mass ratio. Fom this reason, spectra were presented only for the binary mixture of Th with Reality in the ratio 1:1. At the same time, for the binary mixture between Th and Reality material characteristic peaks of the Th can be observed in the spectra.

The FT-IR spectra of the Reality photopolymerized material present the same characteristic peaks as the Nanofil material.

For both binary mixture between the materials and Th or HA photopolymerized, no specific peaksfor Th or HA were observed. 
SEM/EDAX analysis

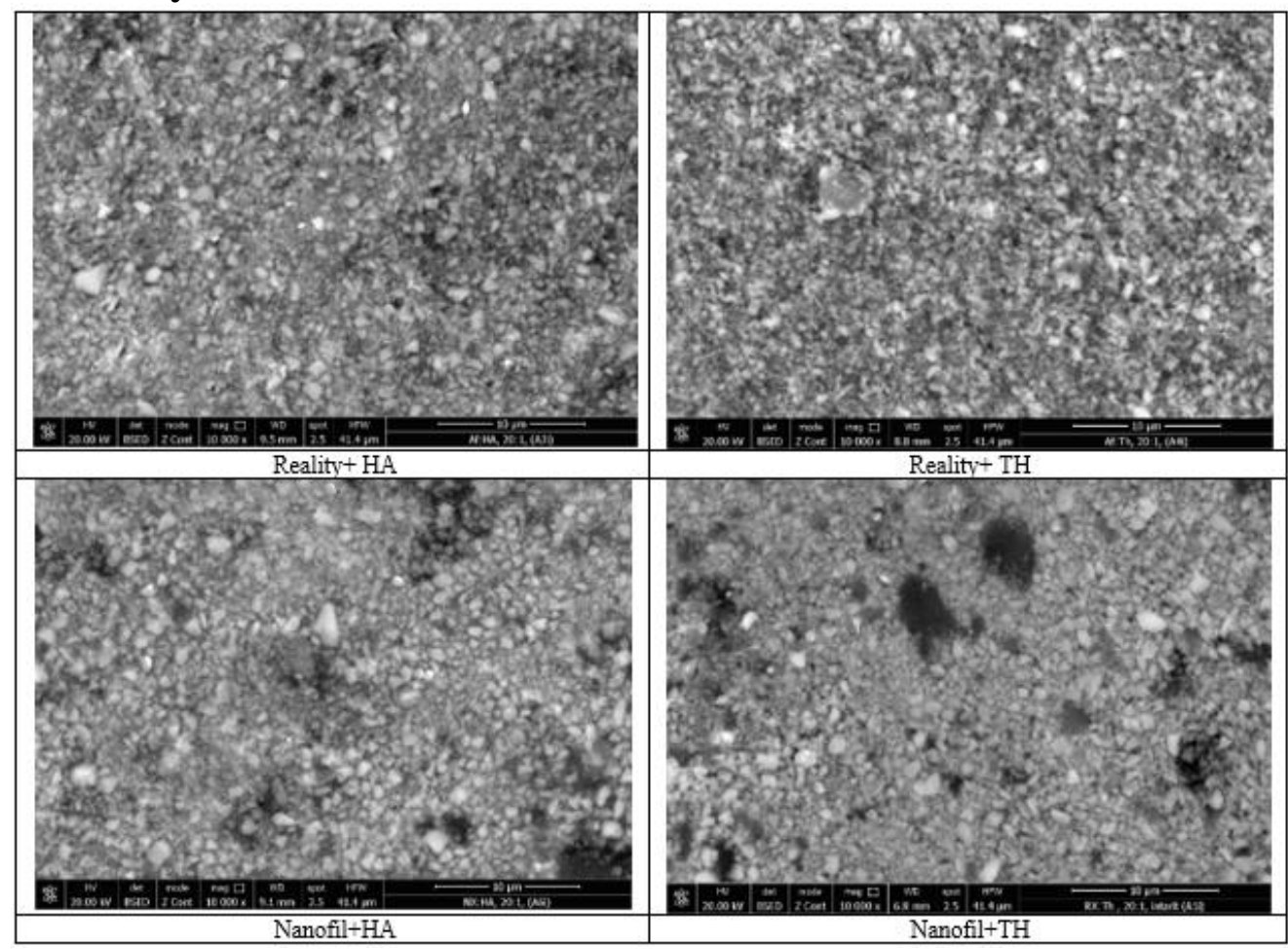

Figure 8. SEM images of studied matherials

The EDAX analysis argues the presence of HA and Th additions, thus appearing in the composition of the obtained material. The data are presented in Table 1.

Table 1. The EDAX results for Nanofil matherials

\begin{tabular}{|c|c|c|c|}
\hline Sample & $\begin{array}{c}\text { Nanofil } \\
\mathbf{W t} \%\end{array}$ & $\begin{array}{c}\text { Nanofil + HA } \\
\mathbf{W t} \%\end{array}$ & $\begin{array}{c}\text { Nanofil + TH } \\
\mathbf{W t \%}\end{array}$ \\
\hline Element & & & 38.67 \\
\hline $\mathrm{C}$ & 31.9 & 30.06 & 0.43 \\
\hline $\mathrm{N}$ & 3.99 & 0.69 & 46.79 \\
\hline $\mathrm{O}$ & 55.21 & 53.43 & 14.12 \\
\hline $\mathrm{Si}$ & 8.90 & 14.58 & - \\
\hline $\mathrm{Ca}$ & - & 0.57 & - \\
\hline $\mathrm{P}$ & - & 0.67 & \\
\hline
\end{tabular}

Table 2. The EDAX results for Reality matherials

\begin{tabular}{|c|c|c|c|}
\hline Sample & \multirow{2}{*}{$\begin{array}{c}\text { Reality } \\
\text { Wt\% }\end{array}$} & $\begin{array}{c}\text { Reality + HA } \\
\text { Wt\% }\end{array}$ & $\begin{array}{c}\text { Reality+ TH } \\
\text { Wt } \%\end{array}$ \\
\cline { 1 - 2 } Element & 19.36 & 26.16 & 26.27 \\
\hline $\mathrm{C}$ & 1.2 & 0.56 & 1.45 \\
\hline $\mathrm{N}$ & 62.01 & 53.48 & 53.52 \\
\hline $\mathrm{S}$ & 17.44 & 19.36 & 18.75 \\
\hline $\mathrm{Ca}$ & - & 0.15 & - \\
\hline $\mathrm{P}$ & - & 0.24 & - \\
\hline
\end{tabular}

The results of the SEM study carried out in a low vacuum atmosphere are shown in Figure 8 . The degree of dispersion of hydroxyapatite and theobromine in the material as well as the porosity of the material is considered. In the presented figures it is observed that in the case of the Reality material with the addition of Th and HA, the mixing leads to a material having a homogeneous distribution, while in the case of the Nanofil material there are areas with a non-homogeneous distribution, but which do not decrease from the material efficiency. This leads us to the conclusion that filler materials can be used as 
fillers and can be effective in the treatment and prevention of dental caries, as well as to prevent further dental destruction.

\section{Conclusions}

Thermal stability of Th in binary mixtures with different dental material and with HA in the solid mixture, in the dynamic oxidative atmosphere, was investigated. Th showed an increased thermal stability, since no mass loss occurs up to $245^{\circ} \mathrm{C}$, due to the structure. As investigational tools for the analysis of the compatibility of Th and of the HA with different dental materials based on methacrylate, thermoanalytical methods and UATR-FTIR spectroscopy have been used. As no interaction between components was observed under environmental conditions, the effect of thermal treatment was investigated. From the FT-IR spectra of the binary mixture of the dental materials studied with Th and HA, no specific peaks for HA and Th can be observed after photopolymerization. The instrumental techniques used can be successfully applied in the characterization of dental materials and can lead to conclusions on how to use them.

As a recommendation, Th can be used for the treatment of early caries. It is recommended to use these materials as successive layers (Th with HA and after that dental material).

\section{References}

1. HUSSEIN M.A. Role of Cross-Linking Process on the Performance of PMMA, IJBSBE, 3 (2017) 279-284.

2.DINESH KUMAR, ANANDAN S. R., EKANTHAMOORTHY J., Advances in dental-pmma based artificial teeth through rapid prototyping technology, Biomed Res., 26 (2015) S6-8

3.GAD M.M., FOUDA S.M., AL-HARBI F.A., R NÄPÄNKANGAS., RAUSTIA A. PMMA denture base material enhancement: A review of fiber, filler, and nanofiller addition, Int. J. Nanomed. 12 (2017) 3801-3812

4. PODARIU A.C., ARDELEAN L., JUMANCA D., GALUSCAN A., RUSU L.C.: Determining the Amount of Volatile Organic Phase in PMMA Dentures. Rev. Chim., 63(7), 2012, 720.

5. PODARIU A.C., GALUSCAN A., JUMANCA D.Influence of Polyethylene Plate Thickness upon the Attrition of Dental Occlusal Appliances, Mater. Plast., 51(4), 2014, 463.

6. GALUSCAN A., JUMANCA D., POPOVICI R., PODARIU A.C., RUSU L.C., STEFANESCU T. SEM Analysis of Hybrid Layer Adhesion in Substances Used for Dentinal Hypersensitivity, Rev. Chim., 67(6), 2016, 1216.

7.BARSZCZEWSKA-RYBAREK I.M., Characterization of urethane-dimethacrylate derivatives as alternative monomers for the restorative composite matrix, Dent Mater J, 30 (2014) 1336-1344

8. ZHONG S., CHEN, J LI. Q., WANG Z., SHI X., LIN K., et al, Assembly synthesis of spherical hydroxyapatite with hierarchical structure, Mater Lett., 194 (2017) 1-4

9. JUMANCA D., SILVASAN H., GALUSCAN A., PODARIU A.C., ARDELEAN L., Rusu L.C. The Use of Hybrid Ionomer-composite Geristore in Restaurations, Rev. Chim., 63(10), 2012, 1024.

10. JUMANCA D., MATICHESCU A., GALUSCAN A., BALEAN O., RUSU L.C. The Effect of Hydroxyapatite from Various Toothpastes on Tooth Enamel, Rev. Chim., 70(7), 2019, 2604.

11.SADAT-SHOJAI M., KHORASANI MT., DINPANAH-KHOSHDARGI E., JAMSHIDI, A. Synthesis methods for nanosized hydroxyapatite with diverse structures, Acta Biomater., 9 (2013) 7591 7621.

12.CHEN F., LIU X., "Advancing biomaterials of human origin for tissue engineering”, PROG POLYM SCI, 53 (2016) 86-168.

13.WILLIAM MM, (1943). Dictionary of Bio-Chemistry and Related Subjects. Philosophical Library. pp. 311, 530, 573. ASIN B0006AQ0NU.

14.MARTÍN MA, RAMOS S. Cocoa polyphenols in oxidative stress: Potential health implications. J Funct. Foods. 2016; 27: 570-588. 
15.NAKAMOTO T, FALSTER AU, SIMMONS WB. Theobromine: A Safe and Effective Alternative for Fluoride in Dentifrices. J Caffeine Res. 2016; 6: 1.

16.MITRA, S.B.; WU, D.; HOLMES, B.N. An application of nanotechnology in advanced dental materials. JADA 2003, 134, 1382-1390

17.ELEY, B.M. The future of dental amalgam: A review of the literature. 2. Mercury exposure in dental practice. Br. Dent. J. 1997, 182, 293-297.

18.ELEY, B.M. The future of dental amalgam: A review of the literature. 4. Mercury exposure hazards and risk assessment. Br. Dent. J. 1997, 182, 373-381.

19.JONES, D.W. A Canadian perspective on the dental amalgam issue. Br. Dent. J. 1998, 184, 581-586. 20.SMART, E.R.; MACLEOD, R.I.; LAWRENCE, C.M. Resolution of lichen-planus following removal of amalgam restorations in patients with proven allergy to mercury salts a pilot-study. Br. Dent. J. 1995, 178, 108-112.

21.MITRA S.B., OXMAN J.D., FALSAFI A., TON T.T. Fluoride release and recharge behavior of a nanofilled resin-modified glass ionomer compared with that of other fluoride releasing materials. Am. J. Dent. 2011, 24, 372-378.

22.BANDAS C., ORHA C., MISCA C., LAZAU C., SFIRLOAGA P., OLARIU S. Photocatalytical inactivation of Enterococcus faecalis from water using functional materials based on natural zeolite and titanium dioxide Chin. J. Chem. Eng., 2014; 22(1):38-43.

23.IVAN C, NICA C.C., DOBRESCU A, BELIC O., MATUSZ P., OLARIU S., Using human intrahepatic bile duct system corrosion casts in training of the medical students and residents. Mater. Plast. 52(1), 2015, 48-50.

24.BEN-NISSAN, B., CHOI, A.H. Sol-gel production of bioactive nanocoatings for medical applications. Part 1: An introduction. Nanomedicine 2006, (1), 311-319.

25.ZOHAIB K. MUHAMMAD Z., SAAD QASIM. SANA S.; MUSTAFA N., AMMAR A. Advances in Nanotechnology for Restorative Dentistry, Materials 2015, 8, 717-731; doi:10.3390/ma8020717 26.CHOI, A.H.; BEN-NISSAN, B.; MATINLINNA, J.P.; CONWAY, R.C. Current perspectives: Calcium phosphate nanocoatings and nanocomposite coatings in dentistry. J. Dent. Res. 2013, 92, 853859. 40.

27.CHOI, C., KIM, Y.A. study of the correlation between organic matrices and nanocomposite materials inoyster shell formation. Biomaterials 2000, 21, 213-222. 41

28. JUMANCA, D., GALUSCAN, A., PODARIU, A., ARDELEAN, L., RUSU, L.C., Nano-hydroxyapatite for Dental Enamel Remineralisation., Rev. Chim., 64(5), 2012, 555.

Manuscript received: 9.12 .2020 